\title{
Restauración y republicanismo: Élites locales y representación política en Alicante (1875-1895)
}

\author{
Rosa Ana GutiérRez Lloret *
}

El sistema político de la Restauración fue diseñado por Cánovas a la medida de un sistema oligárquico que, con el objetivo de erradicar el exclusivismo de partido practicado en la época isabelina, se basaba en una alternancia entre dos grandes partidos dinásticos - conservadores y liberales- que marginaba de hecho a la oposición y fuerzas hostiles al régimen. La Constitución de 1876 y demás leyes que vertebran el modelo teórico en que se asienta el sistema restauracionista sancionaron un régimen liberal oligárquico que, sustentado por dos engranajes básicos: el caciquismo y las "elecciones organizadas», afirmaba el turno dinástico, impidiendo o limitando la participación política de las oposiciones.

Ante el hecho histórico de la Restauración, el republicanismo alicantino se encuentra en una situación de clara debilidad, no sólo por la configuración de un marco político que le es hostil por coincidir con la monarquía restaurada, sino también a consecuencia de su compleja trayectoria en el sexenio precedente ${ }^{\top}$. En los años que median entre la revolución de septiembre y la Restauración alfonsina, el Partido Republicano se vio sometido a un intenso proceso de crecimiento interno que exacerbó sus contradicciones internas favoreciendo la aparición de tendencias. La diversidad de planteamientos ideológicos, políticos y programáticos, en especial los referidos al federalismo y a las reformas

* Universidad de Alicante.

1 GutiérRez LloRet, R. A., Republicanos y liberales. La revolución de 1868 y la 1 República en Alicante, Alicante, 1985. 
sociales, abrirán una profunda brecha en la organización republicana que culmina en 1873, cuando la experiencia de Gobierno pone al descubierto las limitaciones de su gestión y la existencia de dos proyectos nominalmente republicanos pero divergentes en sus contenidos políticos y sociales. El resultado será la ruptura del partido y la configuración de varias formaciones republicanas en los albores de la Restauración ${ }^{2}$.

El republicanismo como fuerza antidinástica se configura como una de las principales oposiciones al sistema y por su ideario democrático, laico y regeneracionista podía haberse convertido en el principal abanderado de una apertura democratizadora del régimen, especialmente en la conflictiva coyuntura finisecular cuando comienzan a aparecer fisuras en el funcionamiento político de la Restauración. Bajo esa perspectiva, el análisis de las oposiciones republicanas en este período no carece de interés y el caso de Alicante presenta una clara singularidad dentro de la diversidad de modelos de funcionamiento político que bajo el esquema general del sistema restauracionista conviven en el Estado español. Una singularidad que se asienta, en primer lugar, en una clara continuidad en la tradición republicana de la ciudad y en la existencia de un republicanismo de signo conservador, estrechamente vinculado a una importante fracción de la alta burguesía local y, en consecuencia, con una influencia política y electoral considerable, no lo suficiente para quebrar el sistema pero sí para integrarse en el mismo, aunque sin superar nunca la subordinación a los partidos dinásticos. Sin embargo, el republicanismo alicantino en los momentos cruciales que enmarcan el cambio de siglo muestra claros síntomas de agotamiento y una incapacidad para vertebrar, por lo menos en el espacio político local, una alternativa movilizadora y modernizadora que contribuyera a una evolución gradual hacia el liberalismo democrático. Son éstos algunos aspectos que se relacionan entre sí y que procuraremos desarrollar a continuación.

\section{EL POSIBILISMO Y LA REORGANIZACIÓN REPUBLICANA EN ALICANTE}

La génesis del partido castelarino deriva de la reagrupación que por la derecha sufrió el antiguo Partido Republicano en 1873. Su origen in-

2 Gutiériez Lloret, R. A., El republicanismo en Alicante durante la Restauración (1875-1895), Alicante, 1989. 
mediato se sitúa en el discurso pronunciado por Emilio Castelar en la sesión parlamentaria del 2 de enero de 1874 que culminó con la entrada en el Congreso de las tropas de Pavía. En él, Castelar sistematizó lo que había sido su actuación en los meses anteriores y definió lo que habría de ser su línea de conducta posterior, confirmándose como el líder del republicanismo más moderado ${ }^{3}$. No obstante, desde los inicios del sexenio venía configurándose una tendencia de signo moderado en el seno de la agrupación republicana alicantina liderada por Eleuterio Maisonnave ${ }^{4}$ que en los últimos años del periodo se convertirá en mayoritaria. Con la Restauración, los republicanos más que atomizarse en varios grupos comenzaron a gruparse en torno a esa fracción moderada que fue la que mantuvo una mayor cohesión tras el desmantelamiento producido por el tránsito a la nueva situación política. Al margen, quedaron algunos grupos minoritarios procedentes del sector federal y del republicanismo de cuño radical que se reorganizarán más tarde, aunque nutriéndose en gran parte de una nueva militancia ${ }^{5}$.

Desde 1876, la permisividad de que gozaron los posibilistas por parte de las autoridades conservadoras facilitó su reorganización. Hacia 1881 podemos decir que concluye el proceso de configuración del partido, denominado «demócrata gubernamental» y más tarde «Partido Republicano Histórico» - nombre que le disputaba el Partido Federal de $\mathrm{Pi}$ - aunque era conocido en los medios políticos como partido "posibilista". A partir de esé momento pasó a ser una "oposición consentida" y, por tanto, una pieza más en el engranaje de la Restauración.

Esa peculiar posición del posibilismo alicantino se relaciona con su base sociológica. Desde el sexenio, el republicanismo venía agrupando políticamente, junto a un numeroso sector de la pequeña burguesía, artesanado y proletariado urbano, a una importante fracción de la alta burguesía comercial y de negocios. Dicha fracción se convirtió en la

${ }^{3}$ Darde Morales, C., "Los partidos republicanos en la primera etapa de la Restauración (1875-1890)", en Jover Zamora, J. M., (Dir.), El siglo xiX en España: doce estudios, Barcelona, 1974, págs. 440.

${ }^{4}$ Eleuterio Maisonnave fue el fundador del Partido Republicano en Alicante. Miembro de la Junta Revolucionaria de 1868, alcalde de la ciudad y diputado a Cortes en varias legislaturas durante el Sexenio Democrático. En 1873 fue ministro de Estado en el Gobierno de Pi y Margall y de Gobernación en los de Salmerón y Castelar. Desde el comienzo de su carrera política se alinea con las tesis castelarinas, siendo considerado como uno de los principales patrocinadores de la Declaración de la Prensa de 1870 y de los máximos exponentes del conservadurismo republicano. Sobre su figura, vid. AlbEROLA, G., Don Eleuterio Maisonnave. Semblanza, Madrid, 1920, y Rico GARCiA, M., Boceto del Excmo. Sr. Eleuterio Maisonnave Cutayar, Alicante, 1890.

${ }^{5}$ Gutiérrez Lloret, R. A., Op. cit., págs. 60-70. 
abanderada de una línea profundamente moderada que cristalizará de forma definitiva con la organización del posibilismo en la Restauración.

Los datos con que contamos para una sociología de la militancia posibilista confirman plenamente la presencia en sus filas de una importante representación de las clases acomodadas locales. Un análisis socio-profesional de los asistentes a un acto político posibilista en 1880 demuestra una presencia más reducida de los sectores populares frente al predominio de la burguesía comercial y profesional ${ }^{6}$. Si profundizamos en este análisis, parece claro que esta formación republicana supo vertebrar en torno suyo a una importante fracción de la alta burguesía local, es decir de la más potente y dinámica a nivel económico, y ello constituye, precisamente, una de las peculiaridades propias del republicanismo alicantino que se convirtió no sólo en la expresión política de la pequeña y mediana burguesía y de sectores obreros, como parece lógico pensar, sino también en la de un destacado sector de las élites dirigentes locales.

Representantes de ese sector republicado de extracción burguesa que se identifica plenamente con el posibilismo serán los hermanos Maisonnave, Juan Leach, Luis Penalva, Amando Alberola, Adolfo Faes, Agustín Bay o la familia Ausó, prototipos de los más activos propietarios, comerciantes $y$, en general, hombres de negocios alicantinos de la Restauración ? La actuación y dinamismo de estos sectores republicanos en la esfera económica alicantina de las décadas finales del siglo XIX, que fue objeto de estudio en otra parte ${ }^{8}$, no deja lugar a dudas y lleva pareja una paralela representación en las instituciones y grupos de presión que canalizaron y defendieron los intereses de la burguesía finisecular como la Sociedad Económica de Amigos del País, la Cámara de Comercio, la Liga de Contribuyentes o los Consejos de Agricultura, Industria y Comercio. En el plano social, esa burguesía republicana participó asimismo de los vínculos endogámicos que articulan la élite oligárquica local ${ }^{9} \mathrm{y}$ de su ascendiente, proyección y activa vida social.

${ }^{6}$ Ibidem, págs. 44-45.

${ }^{7}$ Otros miembros de la burguesia financiera y portuaria alicantina también se sintieron identificados con el republicanismo pero no con el posibilismo, aunque numéricamente constituyen la excepción. Destaquemos, entre ellos, al progresista Román Bono Guarner y al federal Francisco Linares Such.

${ }^{8}$ GutiérRez Lloret, R. A., "Burguesía y republicanismo en el Alicante de la Restauración, 1875-1895", Anales de la Universidad de Alicante. Historia Contemporánea, núm. 7 (En prensa).

${ }_{9}$ Puede comprobarse en los casos de Juan Leach que con su matrimonio con Luisa 
Las importancia de este sector posibilista radica no sólo en la destacada e influyente posición que tuvo en la sociedad alicantina de su tiempo, circunstancia que contrasta ampliamente con la tópica imagen que poseiamos de un republicanismo débil, testimonial y carente de toda proyección en el tejido social de esos años ${ }^{10}$, sino también por su influencia en la dirección del partido, al que logró imprimir un carácter conservador en su ideario y en su propia organización política.

Este es un factor que debemos tener presente a la hora de explicar el proceso de redefinición política y doctrinal, la rectificación de sus relaciones con los núcleos obreristas y la «fácil convivencia» con el sistema de la Restauración de que hacen gala estos republicanos conservadores. La consolidación de una posición social y económica ascendente marcará el giro de su agrupación política - considerada por ellos mismos como la "extrema derecha» del republicanismo- hacia posiciones ideológicas y políticas más moderadas que, en realidad, no difieren demasiado de las propugnadas por el Partido Liberal.

\section{LA DINÁMICA ELECTORAL RESTAURACIONISTA Y EL POSIBILISMO: INTEGRACIÓN Y SUBORDINACIÓN POLITICA}

Como ya ha sido expuesto en numerosos trabajos, las elecciones de la Restauración no son el resultado de un proceso libre y competido, sino de una sistemática falsificación de la voluntad de los electores a través de unos complejos mecanismos de adulteración que, con el propósito de ratificar el turno dinástico e impedir o limitar la participación de las oposiciones, incluían toda una serie de operaciones fraudulentas ${ }^{11}$. Es indu-

Laussat y Cristiernin emparentó con un noble linaje de origen francés vinculado asimismo a las familias Salvetti y Sandoval; y el propio Eleuterio Maisonnave que casará con Luisa Santonja, hija de los condes de Buñol.

10 Los estudio monográficos que van apareciendo sobre el republicanismo durante la Restauración coinciden en señalar que el activismo e influencia de los republicanos en ciertos ámbitos de la vida social y política fue mayor de lo que se suponía. Vid. ARCAS CueEro, F., El respublicanismo malagueño durante la Restauración (1875-1923), Córdoba, 1985; y DUARTE, A., El republicanisme catalá a la fi del segle XIX, Vic, 1985.

"La descripción del funcionamiento político del sistema en VARELA OrTEGA, J., "Los amigos políticos: funcionamiento del sistema caciquistan, Revista de Occidente, núm. 127, (1973), págs. 45-74, y TuselL, J., Oligarquia y caciquismo en Andalucia (1890-1923), Barcelona, 1976. 
dable que estas prácticas dificultaron la participación republicana, favoreciendo una cierta desmovilización electoral y relegando al republicanismo a una posición política subalterna. La propia Ley electoral vigente desde 1878 consagraba algunos mecanismos que, como el sufragio censitario o la creación de un nuevo espacio territorial para las elecciones - la circunscripción de Alicante que agregaba los antiguos distritos de Alicante, Elche y Monóvar, de características socio-económicas muy diversas-, perjudicaban notablemente la participación política de las oposiciones antidinásticas y especialmente a los republicanos.

Con todo, a lo largo de la primera etapa de la Restauración el posibilista Eleuterio Maisonnave sería elegido diputado por la circunscripción de Alicante en tres legislaturas. Con ello se sancionaba la integración del posibilismo en el sistema político restauracionista, pues su elección fue conseguida con el concurso y beneplácito de alguno de los partidos dinásticos ${ }^{12}$.

En 1879 se inaugura la práctica electoral bajo la nueva normativa $y$, por tanto, con sufragio censitario; una circunstancia que por sí sola justificaba el retraimiento republicano. No obstante, los castelarinos, haciendo gala de su benevolencia hacia el nuevo régimen, dan a conocer su posición favorable a la participación y la designación de la candidatura de Eleuterio Maisonnave por la circunscripción de Alicante. Los resultados no les defraudaron, pues el candidato posibilista conseguía el tercer escaño de la circunscripción con un respaldo importante en la ciudad pero con el imprescindible apoyo de su cuñado, el cacique conservador José M. Santoja, en las masas rurales de Elche y Monóvar, lo que provocó las críticas de los sectores liberales sagastinos.

La colaboración de los posibilistas con los conservadores canovistas inauguraba la que habría de ser una práctica usual en los años venideros, pues la disponibilidad del político posibilista le valdrá su elección como diputado en otras dos legislaturas, contando en estas ocasiones con el apoyo liberal. En 1881, con el Partido Liberal de Sagasta en el poder y un margen más amplio de libertad política, la situación ha variado considerablemente de la convocatoria electoral anterior; los posibilistas vuelven a presentar a Eleuterio Maisonnave, que esta vez buscará el apoyo de los liberales aprovechando sus rencillas internas por el control de la representación parlamentaria. Maisonnave ofreció su respaldo a la candidatura de Enrique Arroyo y Adrián Viudes, que era contestada por

12 Hemos analizado de forma más detallada la participación del posibilismo en el sistema político y electoral de la Restauración en GuTiÉRREZ LloRET, R. A., op. cit. págs. 169194. 
otros sectores liberales locales encabezados por Rafael Terol, a cambio de que se le potenciara electoralmente para el tercer escaño. Tras el breve paréntesis de la legislatura iniciada en 1884, en la que el republicanismo posibilista no pudo lograr de nuevo el apoyo de los conservadores, en las elecciones de 1886 con el concurso liberal Maisonnave volvía a ser diputado por Alicante. Los acuerdos tácitos entre liberales y posibilistas funcionaron perfectamente ${ }^{13}$ y unos años después, el entonces diputado liberal Enrique Bushell reconocía públicamente ante el Congreso de los Diputados la existencia de esos pactos y el apoyo gubernamental que tuvo la candidatura de Maisonnave. De sus manifestaciones ha quedado constancia en el Diario de Sesiones:

«...pero en muchos puntos, en las últimas elecciones, los Diputados republicanos, y sobre todo los que, sean o no republicanos, se llaman posibilistas, fueron más candidatos ministeriales que los fusionistas. (EI Sr. Maisonnave: Eso no es verdad). Yo no sé si es verdad o no; lo único que puedo decir es que el gobierno recomendó la candidatura del Sr. Maisonnave en la provincia de Alicante en la forma delicada y digna en que los gobiernos recomiendan estas candidaturas (...) y es un hecho también que por apoyar el gobierno la candidatura del Sr. Maisonnave tuvo que perder integra la candidatura de los tres senadores de la provincia, que salieron de oposición" ${ }^{14}$.

En los días siguientes a la celebración de las elecciones los republicanos posibilistas anunciaban la que habría de ser su línea de actuación en la nueva legislatura. Se alejaban del campo republicano para arropar la política de reformas del Partido Liberal, preludiando to que años después sería de facto la integración de un amplio sector posibilista en la formación liberal:

"Así pues; las minorías republicanas tendrán la obligación de influir con su elocuencia y con sus votos para que tengan próxima realización

${ }^{13}$ Un año más tarde el diario zorrillista La Unión Democrática señalaba que en estas elecciones los fusionistas ofrecieron respaldo electoral a Maisonnave en Elche y otros pueblos de la circunscripción, mientras que los posibilistas arropaban con sus votos la candidatura del liberal Enrique Arroyo, logrando así desbancar al romerista Santonja (Vid. 6 de mayo de 1887).

${ }_{14}$ Diario de Sesiones del Congreso, Legislatura de 1889-1890, sesión del 11 de noviembre de 1889. 
las promesas electorales y de sentido democrático por el gobierno solemnemente contraídas.

Pero al obrar así, las representaciones republicanas de ambas Cámaras, al prestar todo su concurso para que se establezcan el sufragio universal, el matrimonio civil, el juicio por Jurado; el contenido todo de la ley de garantías, deben demostrar que su conducta no obedece a fines bajos (...) Las minorías republicanas deben demostrar que no se trata con ello de preparar el camino para que sea más fácil el advenimiento de la república, sino de realizar única y exclusivamente un acto de nueva justicia, reintegrando en la posesión de sus derechos a los que de ellos habían sido cobardemente desposeidos..." ${ }^{15}$.

Hasta la muerte de Maisonnave en 1890, las relaciones del político posibilista con el sector fusionista de Arroyo fueron excelentes. Una buena prueba de ello fue la coordinación en el trabajo parlamentario que ambos diputados mantuvieron durante las legislaturas de 1881-1883 y 1886-1890, en especial en aquellas cuestiones que afectaban más directamente a la provincia de Alicante. En este contexto, no podemos olvidar la actuación de Maisonnave en el Congreso de los Diputados como portavoz de los intereses de la burguesía vinatera, comercial y portuaria alicantina que le valió el reconocimiento de las instituciones económicas locales en repetidas ocasiones ${ }^{16}$.

Una visión superficial de los resultados electorales de estos años y, más concretamente, la elección de un republicano posibilista en 1879 , 1881 y 1886 podría darnos la imagen distorsionada de un republicanismo que es capaz de quebrar el tinglado caciquil. Nada más lejos de la realidad, pues la elección de Eleuterio Maisonnave, pese a estar arropada por un gran número de votos presumiblemente verídicos ${ }^{17}$, respondió más a las necesidades del encasillado que, como ha señalado Varela Ortega, incluye en ocasiones a candidatos de la oposición antidinástica más moderada para neutralizar asi su capacidad de movilización ${ }^{18}$. Es probable que para los partidos dinásticos fuese preferible tener a Maisonnave en las Cortes que en la oposición, dada la gran influencia que tenía

is El Graduador, 2 de junio de 1886.

${ }_{18}^{18}$ Por ejemplo, en 1887 la Cámara de Comercio le expresó públicamente su reconocimiento por su defensa de las refornas en la legislación mercantil. Vid. Memoria de la Cámara de Comercio de Alicante, leída en Asamblea General celebrada el día 12 de febrero de 1888, Alicante, 1888, pág. 13.

17 En todas las elecciones en las que se presentó, incluso en las de 1884 en que no salió diputado, obtuvo en las mesas de la ciudad de Alicante un número de votos sensiblemente superior al de los candidatos dinásticos.

18 Varela Ortega, J., Op. cit., pág. 49. 
en Alicante. Por otra parte, Maisonnave supo utilizar su prestigio carismático y su habilidad política para celebrar acuerdos tácitos con los grupos dinásticos y aprovechó las coyunturas de rivalidad interna de ellos para afirmar su posición, como ocurrió en 1881 y en 1886 con la fracción de Arroyo, que se aprestó al acuerdo con los posibilistas por no gozar de un total apoyo dentro de la formación liberal al ser cunero. El posibilismo se convertía en una especie de "oposición consentida", integrándose en cierta manera en el sistema político de la Restauración, legitimándolo, contribuyendo a su consolidación y frustrando así cualquier intento de transformación política en un sentido verdaderamente democrático.

Ahora bien, la integración del posibilismo no debe llevarnos a una lectura excesivamente favorable de la proyección política y electoral del republicanismo alicantino durante estos años. La realidad de las elecciones municipales y el turnismo dinástico local nos descubren la otra cara de la moneda: la marginación de los republicanos y nos dan la medida exacta de su subordinación política y de su impotencia frente al sistema de la Restauración. En el funcionamiento político restauracionista los Ayuntamientos y Diputaciones eran instituciones claves del entramado electoral y caciquil. La dinámica electoral de estos años era un proceso en que las elecciones municipales y provinciales son políticamente decisivas por ser aquellas las instituciones que controlaban la maquinaria electoral en los comicios generales y por las amplias posibilidades de patronazgo y clientelismo que abría la hegemonización monopolística de la política institucional local. Por ello, si a nivel estatal el sistema político se caracterizó por el pacto y el turnismo, en el ámbito local y provincial fueron también éstas las notas características de la estructura del poder político ${ }^{19}$. En Alicante los partidos dinásticos monopolizaron la representación política en las instituciones locales durante casi todo el período cronológico que hemos acotado para el presente trabajo y lograron impedir el acceso de los republicanos a la corporación municipal hasta 1889. En las elecciones municipales se utilizaba también el sufragio censitario pero, como este mecanismo de control no era por sí solo suficiente garantía dada la adscripción burguesa de un amplio sector republicano, se aplicaron e intensificaron todo tipo de mecanismos fraudulentos y de presión sobre el electorado local, provocando, en ocasiones, el retraimiento republicano. El resultado fue que los republicanos, que habian

${ }^{19}$ La alternancia gubernamental entre liberales y conservadores producía un reflejo mecánico en la administración local y provincial con el consiguiente relevo del personal político al frente de estas instituciones. 
controlado el Ayuntamiento durante el sexenio revolucionario, se vieron desde 1875 hasia 1889 sisiemáticamente marginados de la escena politica municipal y privados, por tanto, de un campo de actuación que hubiese favorecido su crecimiento y proyección política. En el caso del posibilismo, sus acuerdos tácitos con los grupos dinásticos implicaban, en mayor o menor grado, la aceptación de esa marginación del poder político local.

A modo de conclusión, podemos señalar que el republicanismo posibilista gozó de una nada despreciable implantación y una considerable influencia en determinados ámbitos del tejido social del Alicante finisecular y a ello no fue ajeno los lazos que le unían con un sector de la alta burguesía que, al contrario de otros sectores de la oligarquía local no confluyó ideológica y políticamente en los partidos del arco dinástico, sino que expresó sus inquietudes en ese terreno a través del republicanismo. Se trata de una fracción de la burguesía dominante a nivel social y económico pero que está marginada por su adscripción política de las esferas oficiales del poder político local que hegemonizan conservadores y liberales.

El poder económico e influencia social creciente de este sector republicano forzó su integración en el sistema político de la Restauración que se asentará en un compromiso tácito con los grupos dinásticos, como demuestra la actuación de Maisonnave en la dinámica de las elecciones legislativas. Sin embargo, el compromiso, y como consecuencia la integración política del posibilismo, no se realizó en términos de igualdad, sino que tuvo una clara limitación -la marginación sistemática de las instituciones políticas locales - que pone al descubierto una subordinación que en la práctica le condena a una oposición inoperante.

A lo largo de estos años, los posibilistas siguen defendiendo -cada vez con menor fuerza - un discurso ideológico crítico y reclaman una revisión democrática del sistema que les permita la participación con mayores garantías en la escena política. Pero, al mismo tiempo, su extremada moderación política e ideológica, su acomodación al funcionamiento político restauracionista que les cataloga como una «oposición consentida" y por tanto "domesticada» y su concurso a la estabilidad del sistema, ya que a través de su influencia y control -todavía importantesobre las clases subalternas contribuyen en cierta medida a la cohesión social, crea una clara contradicción y les va separando y restando credibilidad en aquellos sectores o clases sociales e intereses que podían dotar a su discurso de un auténtico contenido rupturista. 
En el tránsito al siglo $x x$, en que el posibilismo - $y$ en general los republicanos - podian haber jugado un significativo papel en la evolución hacia el liberalismo democrático, el republicanismo alicantino entraba en crisis; una crisis que en parte derivaba de su trayectoria anterior $y$, en especial, de las posiciones y prácticas políticas del posibilismo. Los buenos resultados electorales de las legislativas y municipales de 1891 y 1893 sólo alentaron un espejismo pasajero que los comicios siguientes se encargaron de demostrar. La falta de un liderazgo claro tras la desaparición de Maisonnave, de unidad entre sus tendencias y organizaciones y de una renovación en los planteamientos y contenidos programáticos sentenciaron al republicanismo de corte decimonónico. Para los viejos dirigentes posibilistas, tan acomodados a la Restauración, la salida era evidente. Pasarán a las filas del liberalismo dinástico - aunque algunos seguirán algún tiempo en el bando republicano apoyando al centralismo salmeroniano-, mientras los otros grupos republicanos - federales y zorrillistas - se disgregaban por una exacerbación de sus divisiones internas. En el campo liberal dinástico, muchos de estos republicanos, no sólo los posibilistas, pudieron todavía dar cauce en los años siguientes a sus veleidades renovadoras y progresistas identificándose con el proyecto modernizador y democrático que abandera a comienzos de siglo José de Canalejas ${ }^{20}$.

${ }^{20}$ Forner, S., García, M., Cuneros y caciques. Elecciones y políticos en Alicante (1902-1923). (En prensa). 